\title{
Performance of different centrifugal slurry pump impeller configurations when pumping thickened tailings
}

\author{
A. Sellgren Luleå University of Technology, Sweden \\ A. Mustafa Golder Paste Technology Ltd., Canada \\ G. Addie GIW Industries Inc., United States of America \\ L. Whitlock GIW Industries Inc., United States of America
}

\begin{abstract}
The performance for two tailings products has been investigated with a standard closed shroud impeller (diameter $0.3 \mathrm{~m}$ ) and an open shroud type having an auger-like inducer. The tailings products had a median particle size of about 70 and $50 \mu \mathrm{m}$. For the open impeller reductions in water head and efficiency were 7 and 14\% respectively, with the coarser product at solids concentrations by volume of about $47 \%$ when operating in the best efficiency region (BEP). The corresponding reductions were about 10 and $20 \%$ respectively, for the finer product with a slight tendency of increasing reduction in head for very low flow rates. Unstable head curves were observed for flow rates less than about $50 \%$ of the BEP-values with the finer product for the open and closed impeller at 49 and $47 \%$ respectively. When operating within the BEP region for these concentrations, the reduction in efficiency was evaluated at about $20 \%$ for both types of impellers. The slightly higher sensitivity to an unstable head for low flow rates for the standard closed impeller can be weighted to the 10\% higher efficiency compared to the open version with an auger-inducer. The pump performance reduction factors and the pipeline friction losses at a volumetric concentration of $47 \%$ were in the order of 1.5 times larger for the finer product.
\end{abstract}

\section{Introduction}

Centrifugal slurry pumps are used for pumping paste-like thickened tailings short distances and for circulating the slurry in the thickener. In large dredging systems the total pump efficiency including pump and motor has been found to exceed about $70 \%$ with practically negligible effects of solids on the pump performance when pumping various sands at solids concentration by volume of up to $50 \%$ (Whitlock et al., 2004). In the handling of thickened tailings slurries smaller pumps are used where the performance de-rating has been related to the yield stress or to a characteristic viscosity.

A thickened tailings product was simulated with clay slurry to which a fine sand (135 $\mu \mathrm{m})$ was successively added to increase the consistency at the GIW Hydraulic Laboratory, (Sellgren et al., 2005). They found in tests with a $0.3 \mathrm{~m}$ diameter 3 -vane open shroud impeller with a flow inducer that a stable head was produced at a yield stress well above $200 \mathrm{~Pa}$ with reductions in water head and efficiency of 10 and $15 \%$ respectively.

Few studies on the pump performance with authentic tailings slurries are available. Cooke (2007) presented results for various tailings products for solids concentrations by volume of up to $39 \%$ with yield stresses from 60 to nearly $100 \mathrm{~Pa}$. He reported head and efficiency reductions of less than about $10 \%$ with a standard centrifugal slurry pump with a $0.365 \mathrm{~m}$ diameter impeller.

The objective is to present resulting reductions in water head and efficiency for a three-vane all metal pump with an impeller diameter of $0.3 \mathrm{~m}$ based on pilot-scale loop tests with two tailings products. Two impellers were used, one was a standard closed shroud version and the other was an open shroud type having a simple auger-like inducer. The aim is also to briefly discuss some yield-related mechanisms within a pump and to characterize the pipeline loop test results. 


\section{Effects of solids on pump head and efficiency}

The pump head and efficiency when pumping water are generally lowered by the presence of solids. When pumping slurries, the relative reduction of the clear water head and efficiency for a constant flow rate and rotary speed may be defined by the ratios and factors shown in Figure 1.

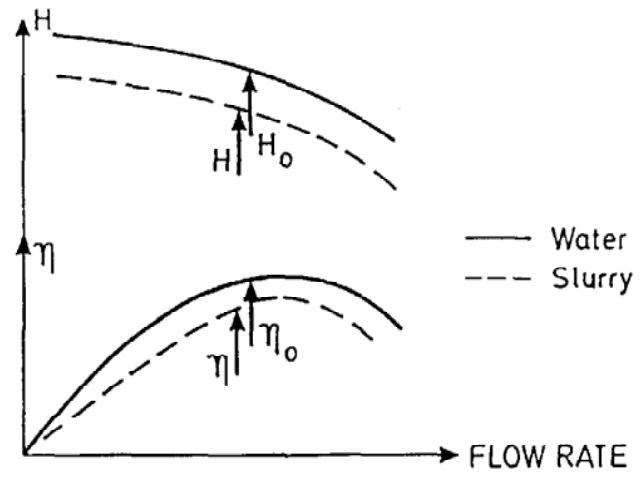
Head ratio:
$\mathrm{HR}=\mathrm{H} / \mathrm{H} 0 \quad$ Efficiency ratio:
$\mathrm{ER}=\eta / \eta_{0}$
Head reduction factor:
$\mathrm{R}_{\mathrm{H}}=1-\mathrm{HR}$
Efficiency reduction factor:
$\mathrm{R}_{\eta}=1-\mathrm{ER}$

Figure 1 Sketch defining the reduction in head and efficiency of a centrifugal pump transporting a solid-water mixture. $\mathrm{H}$ and $\mathrm{H}_{0}$ are head in metres of slurry and water respectively. Efficiencies in slurry and water service are denoted $\boldsymbol{\eta}$ and $\eta_{0}$ respectively

To be able to produce a required head, $\mathrm{H}$, of slurry, the pump must be capable of producing a head of water, $\mathrm{H}_{0}$ :

$$
\mathrm{H}_{0}=\mathrm{H} / \mathrm{HR}
$$

which means that the pump has to be increased to a higher rotary speed at which the water efficiency is, $\eta_{\mathrm{o}}$. The total efficiency, $\eta_{\mathrm{T}}$, for the pump system can then be expressed in the following way with the definition of $\mathrm{R}_{\eta}$ :

$$
\eta_{T}=\eta_{M} \cdot \eta_{O}\left(1-R_{\eta}\right)
$$

where the power lost in the motor and in the transmission corresponds to an efficiency factor, $\eta_{\mathrm{M}}$, related to the pump efficiency, $\eta_{0}$.

\section{Experimental set-ups and procedures}

Golder Paste Technology Ltd is involved in the design of thickened tailings handling systems for underground filling and surface disposal all over the world. Golder Paste and the GIW Hydraulic Laboratory, U.S.A. have performed several pipeline loop and pump performance tests for different tailings products. Golder supplied a membrane type of positive displacement pump to facilitate volumetric solids concentrations in excess of 50\% and loading and priming the loop system. Golder representatives also carried out and evaluated the slump measurements.

The system with the positive displacement pump and the test pump was set up in a way that allowed either pump to be used, see Figure 2. Both pumps took suction from the $0.44 \mathrm{~m}$ in diameter by $1.8 \mathrm{~m}$ tall surge tank. The discharge from the positive displacement pump was routed to connect into the $0.075 \mathrm{~m}$ diameter test loop system just downstream of the centrifugal pump. 


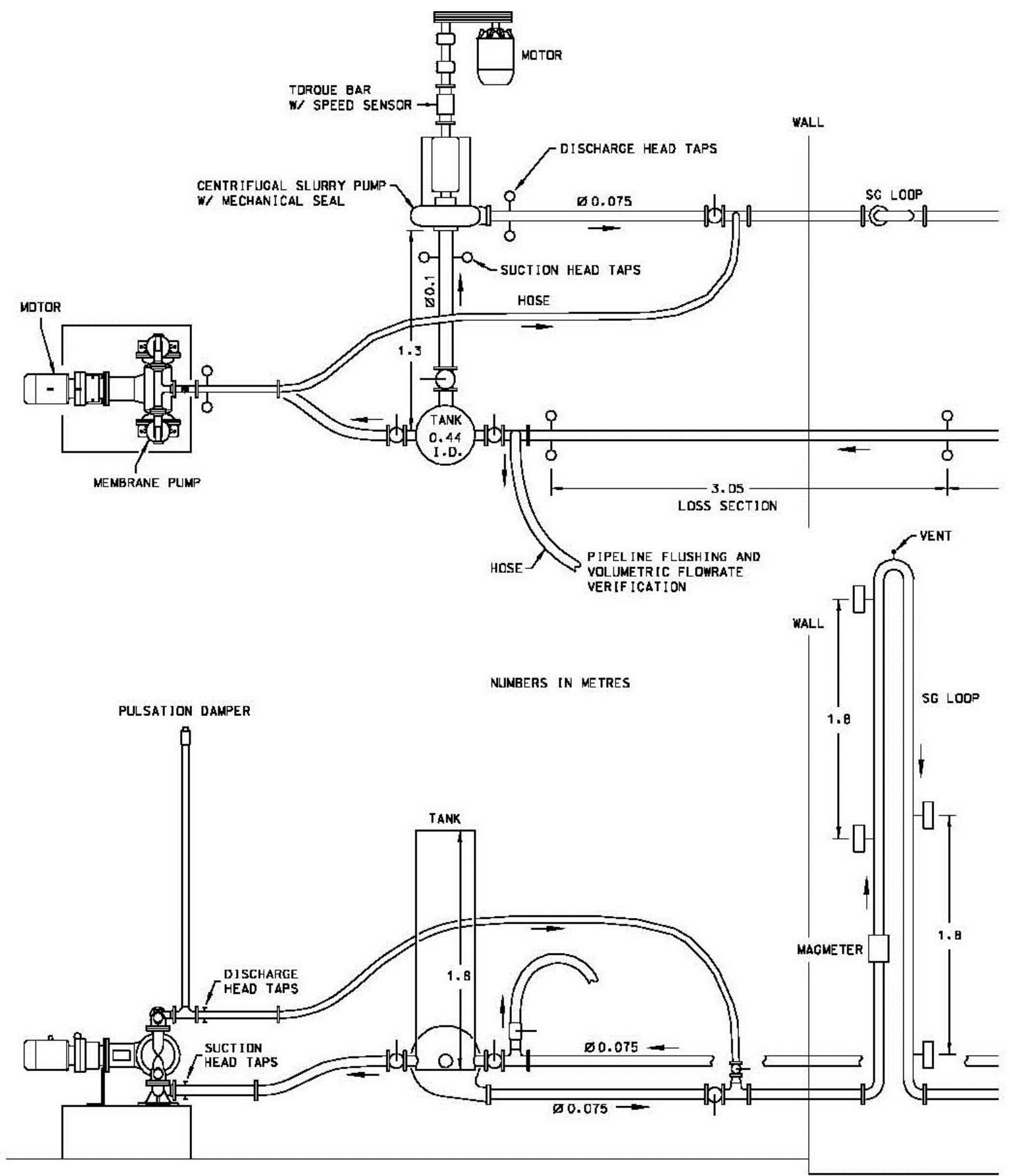

Figure 2 Experimental set-up. The closed loop pipe system was a modification of the GIW Hydraulic Laboratory $0.075 \mathrm{~m}$ in diameter test loop with a $0.15 \mathrm{~m}$ head loss section added. Only the out-and ingoing part of the loop can be seen to the right

The centrifugal pump was used as the main test pump after the system was loaded, primed and bled of air, and the slurry diluted to a maximum solids concentration by volume of about $49 \%$. The pump was an all metal pump with a semi-volute shell, $0.1 \mathrm{~m}$ diameter suction inlet, $0.075 \mathrm{~m}$ discharge and a $0.3 \mathrm{~m}$ diameter three-vane impeller.

During testing the discharge from the centrifugal pump proceeded through the vertical inverted U-loop for slurry density measurement and the magnetic flowmeter seen to the right in Figure 2. The downstream head loss section in the loop, about $10 \mathrm{~m}$ long, $0.15 \mathrm{~m}$ in diameter and the returning $0.075 \mathrm{~m}$ in diameter head loss section to the tank are not seen in Figure 2. In order to provide better mixing and release of entrained air, a 
modification of the piping was made to discharge the slurry vertically downward into the centre of the tank near the top and submerged just below the slurry level. This modification is not shown in Figure 2.

Pump solids effect results were mainly obtained for flow rates in the range of 60-100\% of the best efficiency point (BEP). Centrifugal pump rotary speeds varied mainly from $600-1,700 \mathrm{rpm}$ in order to collect data over a wide range of pipeline velocities. Measured head data were scaled to a fixed speed of 1,000 rpm for comparison to water test values at that rotary speed. For centrifugal pumps, the mechanical losses become more significant at lower speeds which may affect the efficiency results. Therefore, only efficiency data points above $900 \mathrm{rpm}$ were evaluated against the corresponding 1,000 rpm water test data. However, the scaling procedure for efficiency also means that the solids effect is seemingly reduced close to the BEP. Resulting reduction values based on the parameters introduced in Figure 1 have therefore mainly been based on evaluations close to $1,000 \mathrm{rpm}$.

\section{$4 \quad$ Results}

Representative particle size distributions of the delivered tailings products are shown in Table 1. Solids density $=2,710 \mathrm{~kg} / \mathrm{m}^{3}$.

Table 1 Particle size distributions for the two tailings products

\begin{tabular}{lll}
\hline Product & A & B \\
\hline $\mathrm{d}_{\max } \mu \mathrm{m}$ & 400 & 400 \\
$\mathrm{~d}_{85} \mu \mathrm{m}$ & 190 & 175 \\
$\mathrm{~d}_{50} \mu \mathrm{m}$ & 70 & 50 \\
$\%<40 \mu \mathrm{m}$ & 32 & 41 \\
$\%<20 \mu \mathrm{m}$ & 21 & 32 \\
\hline
\end{tabular}

Operation with the positive displacement pump was carried out with both products at a solids concentration by volume of up to about $53 \%$ corresponding to a concentration by mass of about $76 \%$. Velocities in the $0.152 \mathrm{~m}$ diameter pipeline were mainly from $0.5-1 \mathrm{~m} / \mathrm{s}$ with this pump. Start up after an hour long stop was performed without problems. Pipeline shear stresses were in the range of 200-400 $\mathrm{Pa}$ with the finer Bproduct giving the highest wall stresses.

The solids content in the slurry will be expressed in terms of the volumetric concentration, C. The corresponding slurry density ratio (S.G) and solids concentrations by mass are given in Table 2.

Table 2 Solids content expressed in volumetric and mass concentrations and slurry density ratio (S.G)

\begin{tabular}{lllll}
\hline Vol. conc., C\% & 35 & 40 & 47 & 49 \\
Slurry S.G. & 1.6 & 1.7 & 1.8 & 1.85 \\
Mass. conc, \% & 59 & 64 & 71 & 72 \\
\hline
\end{tabular}

The consistency of highly thickened tailings is at times referred to in terms of the settling or "slump", adapted from the standard method in the concrete industry. Observed values for very high solids concentrations from the positive displacement pump data are shown in Figure 3. 


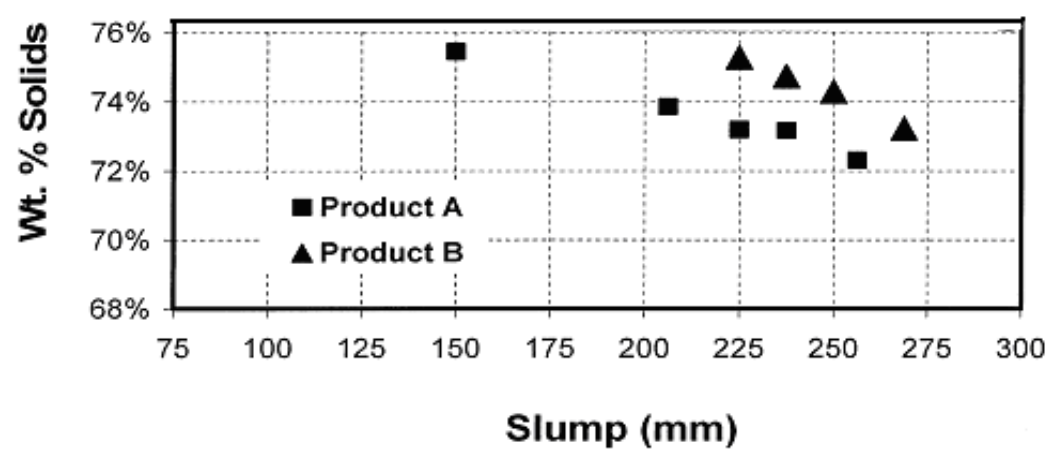

Figure 3 Slump results for the two products versus the solids concentration by mass

It follows from Figure 3 how the coarser A-tailings had a smaller slump than the finer B for a constant solids content and that the slump varied linearly with the concentration by mass. No further reference will be made to the slump data in this paper.

\subsection{Effects of solids on centrifugal pump head and efficiency}

The effect on the head and efficiency for the finer B-tailings with the closed and open impellers is shown in Figures 4 and 5 respectively, for C from 35 to about $40 \%$. Result for the open impeller for the coarser Aproduct at $47 \%$ is shown in Figure 6. Figure 7 contains the open impeller data for C of 47 and $49 \%$ for the finer B- product while Figure 8 shows the same for the closed impeller.

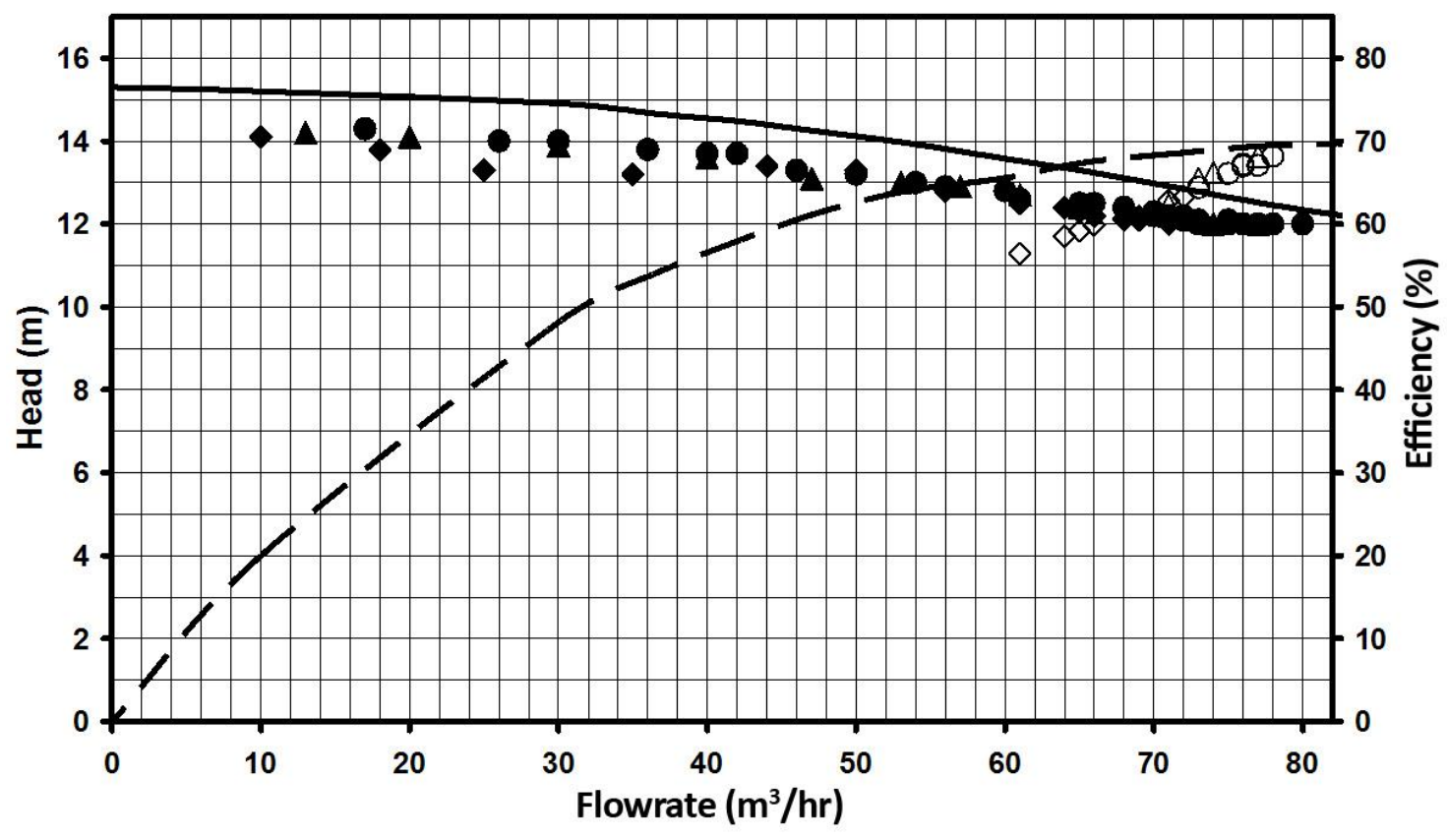

$\begin{array}{rccc}\text { Volumetric conc., C\% } & 35 & 37.5 & 40 \\ \text { Head } & \bullet & \Delta & \bullet \\ \text { Efficiency } & \circ & \Delta & \diamond\end{array}$

Figure 4 Pump solids effect for the finer B-product at $35<\mathrm{C}<40 \%$ with closed impeller. Full and dashed lines represent clean water head and efficiency respectively 


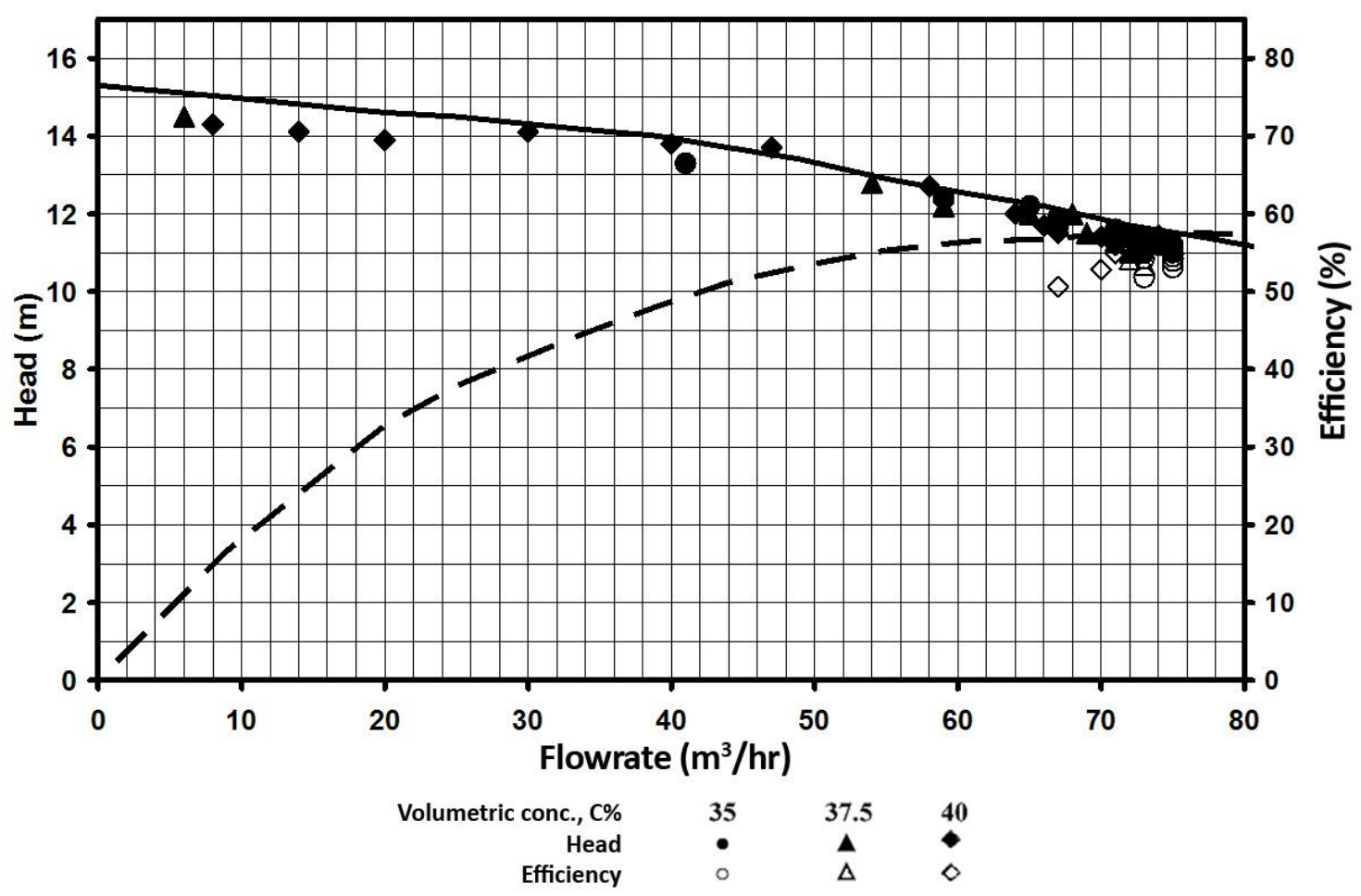

Figure 5 Pump solids effect for the fine B-product with open impeller at $35<\mathrm{C}<40 \%$

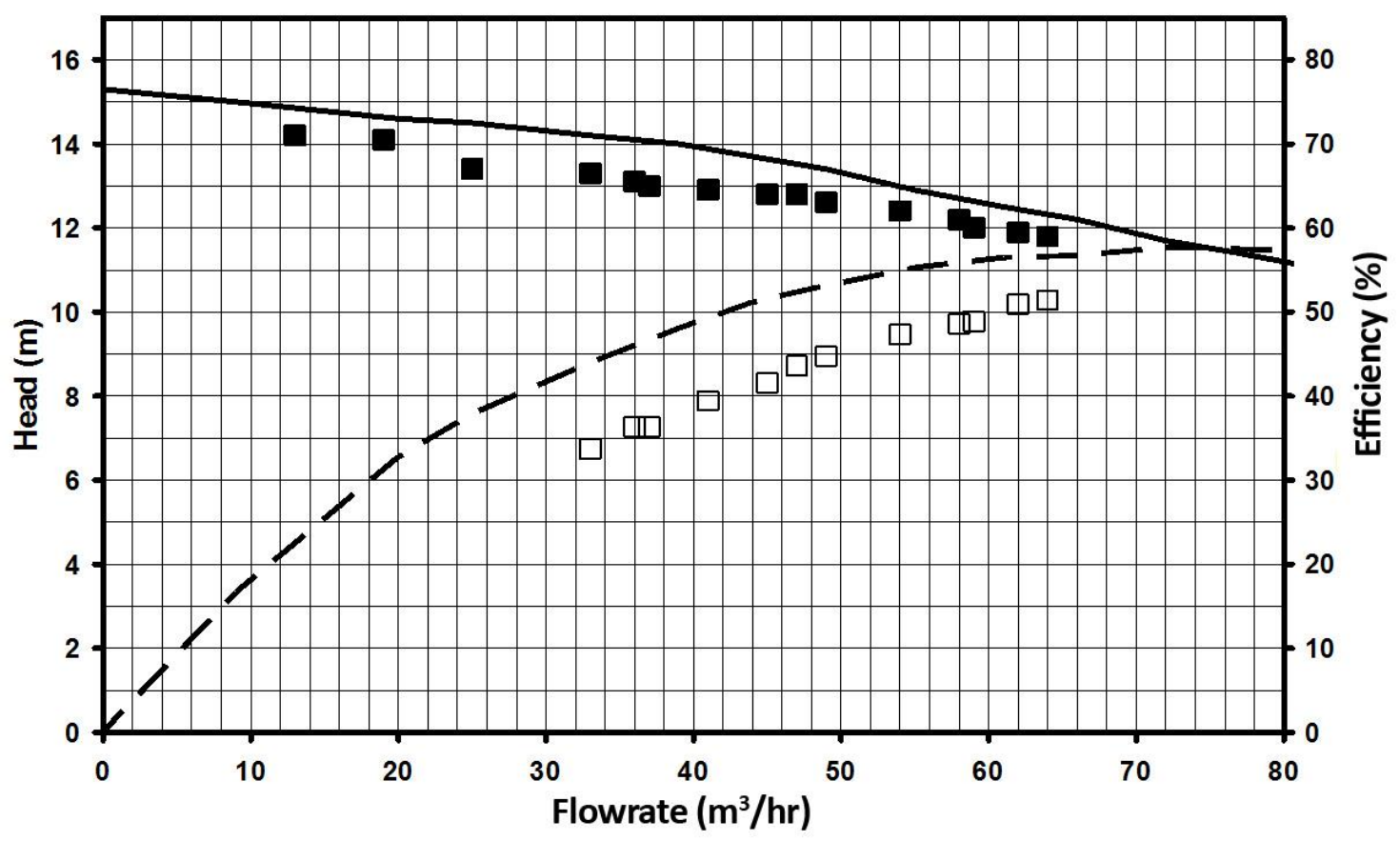

Head Efficiency

Figure 6 Pump solids effect for the coarser A-product with open impeller for C about $47 \%$ 


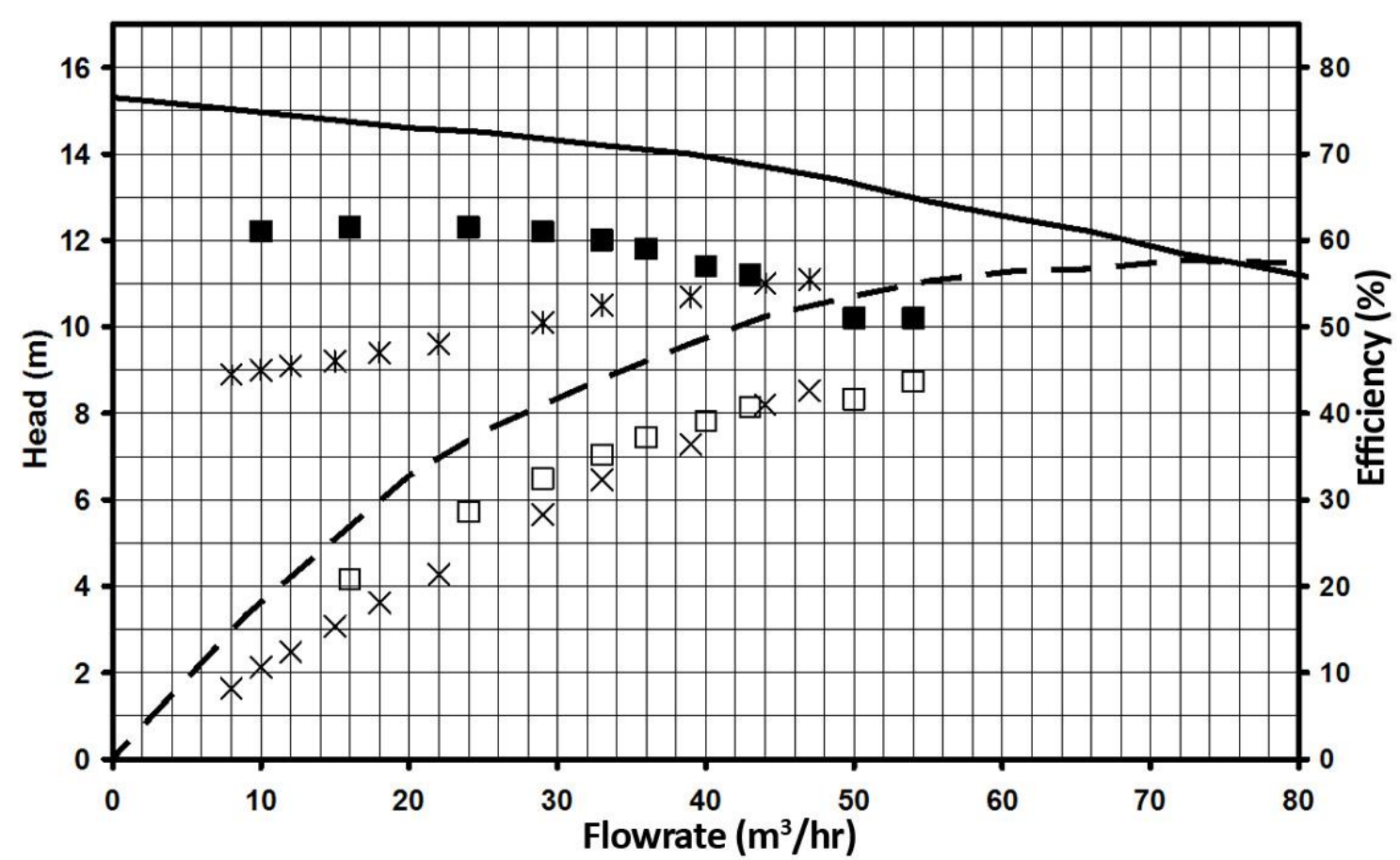

$\begin{array}{rrr}\text { C\% } & 47 & 49 \\ \text { Head } & \square & * \\ \text { Efficiency } & \square & \times\end{array}$

Figure 7 Pump solids effect for the finer B-product at C values of 47 and $49 \%$ with open impeller

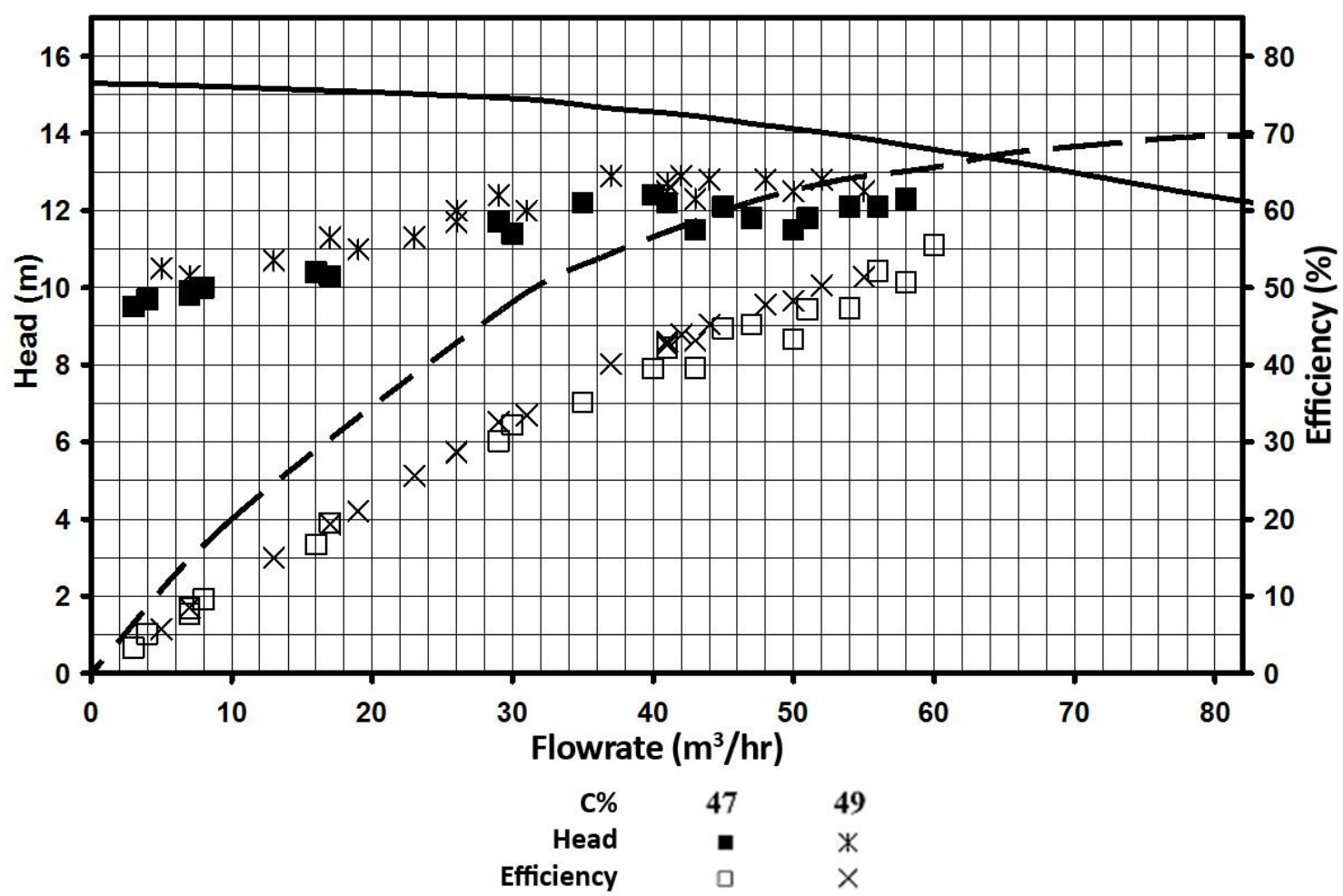

Figure 8 Pump solids effect for the finer B-product with closed impeller; $\mathrm{C}=47$ and $49 \%$

It follows from Figures 4 and 5 for both impellers and the finer B-tailings at C-values from 35 up to about $40 \%$ that the reductions in head and efficiency were small and about 4 and $7 \%$ respectively, following the 
definitions in Figure 1. This means that the efficiency when pumping slurry is the water efficiency times $(1-0.07)=0.93$.

For $\mathrm{C}$ about $47 \%$ in Figure 6 for the open impeller and the coarser A-product the reductions in head and efficiency were about 7 and 14\% respectively. With the finer B-product in Figure 7 the corresponding values were about 10 and $20 \%$ with a slight tendency of a lowering in the head at about $25 \%$ of the BEP-flow rate. The results also show that the solids de-rating affect was about 1.4 times larger for the finer product.

It can be seen in Figures 7 and 8 how the measured heads become unstable for flow rates less than about $50 \%$ of the BEP-value with the finer product for the open and closed impeller at 49 and $47 \%$ respectively. When operating within the BEP region for these concentrations, the reduction in efficiency was estimated to about 20\% for both type of impellers. The corresponding reductions in head for the open and closed impellers were estimated to 10 and $15 \%$ respectively.

\subsection{Pipeline results}

Resulting pipeline wall shear stresses for the coarser A-product versus the pseudo shear rate 8V/D are shown in Figure 9 for $\mathrm{C}$ from 35 to $49 \%$. V is velocity and D pipeline diameter. The corresponding shear stresses for the B-product are shown in Figure 10 for C from 35 to 47\%. Figures 9 and 10 contain both the $0.075 \mathrm{~m}$ diameter and $0.152 \mathrm{~m}$ friction loss data. The large diameter data correspond to 8V/D less than about 75 .

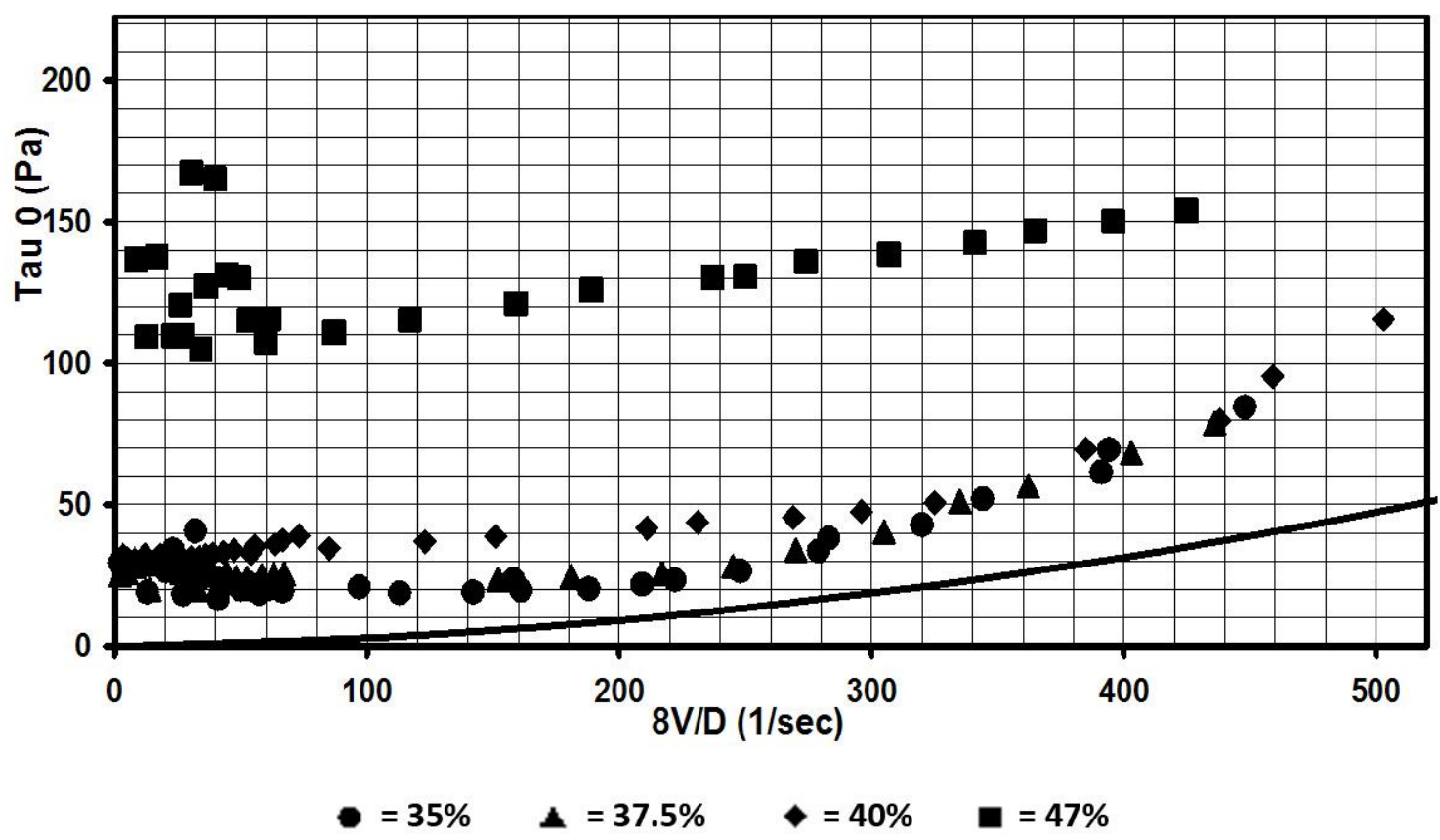

Figure 9 The coarser A-tailings pipe wall shear stress versus the pseudo shear rate 8V/D 


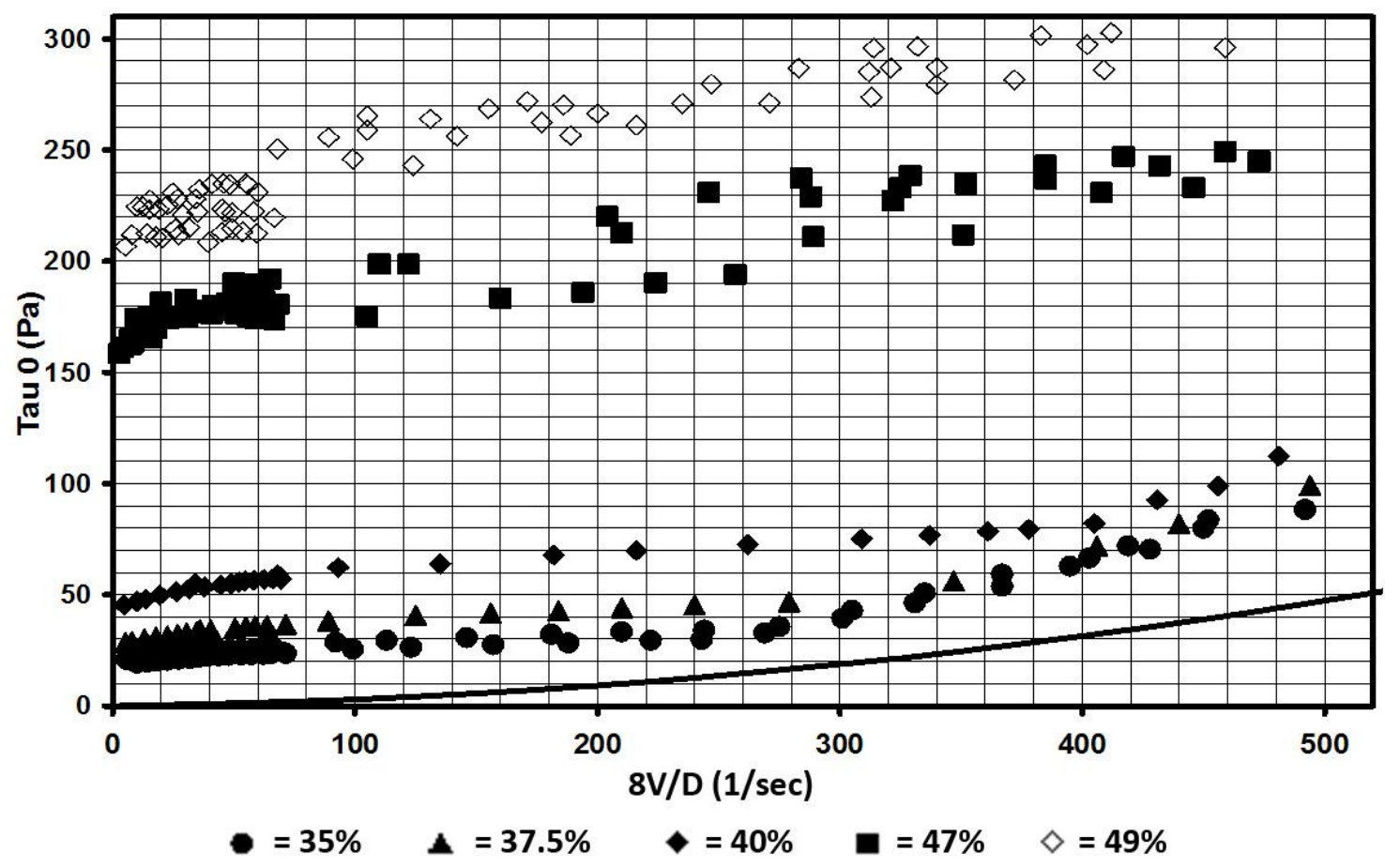

Figure 10 Tailings B pipeline wall shear stress versus the pseudo shear rate 8V/D

The results in Figures 9 and 10 show how the finer B-product corresponds to a higher resistance to pipeline flow at higher solids concentrations. The largest shear stresses for the $47 \%$ data with the finer B-tailings in Figure 10 were from start-up after about 12 hours for a temperature of about $20^{\circ} \mathrm{C}$.

The smaller losses were from the end of a long test period when the temperature reached $47^{\circ} \mathrm{C}$. The scatter seen here corresponded to the longest exposure time in the loop, and maximum temperature difference.

It follows from Figure 9 for the coarser A-product that the wall shear stress exceeded $100 \mathrm{~Pa}$. The corresponding pressure gradient then exceeds about $2.7 \mathrm{kPa} / \mathrm{m}$ in a $0.15 \mathrm{~m}$ diameter pipeline. The erratic nature of some results in Figure 9 for 8V/D below about 75 1/s corresponds to depositional and bed forming tendencies in the $0.152 \mathrm{~m}$ diameter pipeline for velocities lower than about $1.4 \mathrm{~m} / \mathrm{s}$.

A transition from laminar to turbulent flow can be seen in Figure 10 at $8 \mathrm{~V} / \mathrm{D}$ about 400 for $\mathrm{C}$ about $40 \%$ corresponding to a velocity of about $3.8 \mathrm{~m} / \mathrm{s}$. The transition velocity for $\mathrm{C}$ about $35 \%$ was evaluated to about $2.6 \mathrm{~m} / \mathrm{s}$ at $8 \mathrm{~V} / \mathrm{D}$ about $280 \mathrm{l} / \mathrm{s}$.

The results shown in Figures 9 and 10 represent for the largest concentrations a laminar and highly nonNewtonian and yield-like behaviour. A characteristic pipeline yield stress can be estimated by extrapolating the curves back to the vertical axis.

The friction losses for the finer B-tailings were larger than for the coarser product when compared at the same volumetric concentration. For example, it follows from Figure 9 and 10 at $C=47 \%$ that pipe wall stresses are about 1.6 larger for 8V/D-values in excess of 100 .

\section{$5 \quad$ Discussion and conclusions}

The following relationship often holds for Bingham type slurries for approximate estimations of the transition velocity $V_{T}$, see for example (Wilson et al., 2006).

$$
V_{T} \approx 22.5 \sqrt{\tau_{y} / \rho}
$$

where $\tau_{\mathrm{y}}$ is the yield stress and $\rho$ slurry density. With the $\mathrm{V}_{\mathrm{T}}$-values observed here in Figure 10 inserted in Equation (3) for the slurry densities corresponding to $\mathrm{C}=30$ and $35 \%$, calculated yield stresses of 50 and $30 \mathrm{~Pa}$ for of 3.8 and $2.6 \mathrm{~m} / \mathrm{s}$ respectively, corresponded reasonable well to observed values. For a 
concentration of $47 \%$, pressure gradients exceeded $2 \mathrm{kPa} / \mathrm{m}$ in the $0.15 \mathrm{~m}$ diameter pipeline, thus fulfilling the rough criterion for sufficient pressure gradient to transport a highly concentrated slurry with a bed-like behaviour (Cooke, 2002).

The performance for two tailings products has been investigated for a standard closed shroud impeller (diameter $0.3 \mathrm{~m}$ ) and an open shroud type having an auger-like inducer. The tailings products had a median particle size of about 70 and $50 \mu \mathrm{m}$. The pump performance reduction factors and the pipeline friction losses at a volumetric concentration of $47 \%$ were in the order of 1.5 times larger for the finer product.

- For the open impeller reductions in head and efficiency were 7 and $14 \%$ respectively, with the coarser product at a solids concentration by volume of about $47 \%$ when operating in the best efficiency region (BEP). The corresponding reductions were about 15 and $20 \%$ respectively, for the finer product with a slight tendency of increasing reduction in head for very low flow rates.

- Unstable head curves were observed for flow rates less than about $50 \%$ of the BEP-values with the finer product for the open and closed impeller at 49 and $47 \%$ respectively. When operating within the BEP region for these concentrations, the reduction in efficiency were estimated to about $20 \%$ for both type of impellers. The corresponding reductions in head for the open and closed impellers were estimated to 10 and $15 \%$ respectively.

- The slightly higher sensitivity to an unstable head for low flow rates for the standard closed impeller can be weighted to the $10 \%$ higher efficiency compared to the open version with an auger-inducer.

Bootle (2006) reported de-rating results for a 4-vane semi open $0.244 \mathrm{~m}$ impeller pump modified with an enlarged suction inlet from 0.1 to $0.186 \mathrm{~m}$ and integrated flow inducer scoops, which project into the inlet. This pump had a water efficiency that was about $10 \%$ lower than the corresponding standard pump. Bootle (2006) used high and low yield stress kaolin slurries with C-values of 28 and 37\% with yield stresses of $200 \mathrm{~Pa}$ and 7.5 $\mathrm{Pa}$ respectively. A chemical additive was used to reduce the yield stress. The corresponding plastic viscosities were 0.14 Pa.s and 0.018 Pa.s. Both viscous properties resulted practically in the same reductions in efficiency, ER about 0.83 , with no reductions in head. In terms of the large difference in yield stresses and related apparent viscosities for laminar flow, the results indicate that de-rating effects were coupled to high shear rates or high velocity effects (Xu et al., 2002), i.e. limited effects of the yield stress.

In a modelling approach of unstable head tendencies linked to the yield property, Wilson and Sellgren (2006) discussed mechanisms related to a strong non-Newtonian behaviour. Build-up of material within the pump may modify the flow passages that promote losses.

A yield stress is not necessarily a determining factor for the development of an unstable head curve (Wennberg et al., 2008), following results by Kabamba (2007) for a CMC-fluid with pseudoplastic property. Kabamba used a 0.2 by $0.1 \mathrm{~m}$ all metal 5-vane pump with an impeller diameter of $0.365 \mathrm{~m}$.

In summary, it appears that there is no unique coupling of de-rating processes to a distinct flow regime within a centrifugal pump for the type of slurries discussed here. Further work will be directed to different flow mechanisms together with experimental evaluations for different pump configurations, designs and sizes.

The performance de-rating results confirmed the importance of operating close to BEP and considering about $200 \mathrm{~Pa}$ as a practical upper limit yield stress as pointed out by (Cooke, 2007) for highly thickened tailings with the size of pumps studied here with impeller diameters of less than about $0.4 \mathrm{~m}$.

\section{References}

Bootle, M.J. (2006) Practical aspects of Transporting Past with Rotodynamic Slurry Pumps, in Proceedings Ninth International Seminar on Paste and Thickened Tailings (Paste06), R.J. Jewell, S. Lawson and P. Newman (eds), 3-7 April 2006, Limerick, Ireland, Australian Centre for Geomechanics, Perth, pp. 413- 427.

Cooke, R. (2002) Laminar flow settling: the potential for unexpected problems, in Proceedings 15th International Conference on Hydrotransport, Banff, Canada, 3-5 June, pp. 121-133.

Cooke, R. (2007) Thickened and paste tailings pipeline systems-Design procedure, part 2, in Proceedings Tenth International Seminar on Paste and Thickened Tailings (Paste07), A.B. Fourie and R.J. Jewell (eds), 13-15 March 2007, Perth, Australia, Australian Centre for Geomechanics, Perth, pp. 129-140. 
Kabamba, B.M. (2007) Evaluation of derating procedures for centrifugal pump performance, Magister Technologiae thesis, Cape Peninsula University of Technology, South Africa.

Sellgren, A., Addie, G. and Whitlock, L. (2005) Technical-Economical Feasibility of Using Centrifugal Pumps in High-Density Thickened Tailings Slurry Systems, in Proceedings 11th International Seminar on Paste and Thickened Tailings (Paste08), A.B. Fourie, R.J. Jewell, P. Slatter and A. Paterson (eds), 5-9 May 2008, Kasane, Botswana, Australian Centre for Geomechanics, Perth, pp. 195-206.

Wennberg, T., Sellgren, A. and Whitlock, L. (2008) Predicting the performance of centrifugal pumps when handling complex slurries, in Proceedings 14th International Conference on Transport and Sedimentation of Solids particles, June 23-25, St Petersburg, Russia, pp. 324-333.

Whitlock, L., Sellgren, A. and Addie, G.R. (2004) Energy requirements for pumping sand slurries, comparison of largescale loop and field results with a design model, in Proceedings WEDA XXIV and Texas A and M Annual Dredging Seminar, Orlando, Florida U.S.A., pp. 22-35.

Wilson, K.C., Addie, G.R., Sellgren, A. and Clift, R. (2006) Slurry transport using centrifugal pumps, 3rd Blackie Academic and Professional (Chapman and Hall), London, U.K.

Wilson, K.C. and Sellgren, A. (2006) Effect of strongly non-Newtonian slurries on the head and efficiency of centrifugal pumps, in Proceedings 11th International conference on transport and sedimentation of solid particles, Georgia, September.

Xu, J., Tipman, R., Gillies, R. and Shook, C.A. (2002) Centrifugal pump performance with Newtonian and nonNewtonian slurries, in Proceedings 15th International Conference on Hydrotransport, Banff, Canada, 3-5 June, pp. 693-710. 
